\title{
The Meta-Analysis of Crossover Studies on Exercise and Appetite-Related Hormones
}

\author{
Greg Atkinson • Jessica A. Douglas • \\ David J. Stensel
}

Published online: 24 April 2014

(C) Springer International Publishing Switzerland 2014

\section{Dear Editor,}

Schubert et al. [1] systematically reviewed studies on the acute effects of exercise on hormones related to appetite regulation. A meta-analysis was incorporated to quantify the pooled effect sizes (and corresponding $95 \%$ confidence intervals) for the difference in area-under-the-curve responses between an exercise condition and a control (noexercise) condition.

The meta-analysis of crossover studies is not straightforward. Elbourne et al. [2] discussed the various options for meta-analysing crossover designs. The least preferable option was to ignore the crossover nature of the design and, thereby, disregard the paired (within-subjects) nature of the data. In this approach, the effect sizes are meta-analysed as if the study designs are two-group, randomised, controlled trials. This approach was deemed to violate the assumption of case independence and to be too conservative [2].

We wonder to what extent Schubert et al. [1] accounted for the crossover nature of the studies? For example, there was no information regarding the imputation of a paired correlation coefficient in the meta-analysis to arrive at standard errors and confidence intervals that reflect the crossover nature of the study designs.

In many of the reviewed studies (e.g. 3), the difference in area-under-the-curve ghrelin between exercise and control trials was reported by the original study authors to be statistically significant. Nevertheless, the $95 \%$ confidence intervals calculated in [1] overlap zero for all but 1 of the 25 studies on ghrelin (see forest plot). In the supplementary file [1], the associated $P$ values are calculated to be not statistically significant for all but one of the studies on ghrelin. Perhaps this discrepancy could be because the paired nature of the data at the individual study level has been overlooked, resulting in confidence intervals and $P$ values for the overall and subgroup effect sizes that are biased wide and high, respectively.

Acknowledgments There was no financial support for this study.

\section{References}

1. Schubert MM, Sabapathy S, Leveritt M, et al. Acute exercise and hormones related to appetite regulation: a meta-analysis. Sports Med. 2014;44:387-403.

2. Elbourne DR, Altman DG, Higgins JPT, et al. Meta-analysis involving cross-over trials: methodological issues. Int J Epidemiol. 2002;31:140-9.

3. Broom DR, Batterham RL, King JA, et al. Influence of resistance and aerobic training on hunger, circulating levels of acylated ghrelin, and peptide YY in healthy males. Am J Physiol Regul Integr Comp Physiol. 2009;296(1):R29-35.
G. Atkinson $(\square)$

Health and Social Care Institute, School of Health and Social

Care, Teesside University, Parkside West, Middlesbrough,

Tees Valley TS1 3BA, UK

e-mail: greg.atkinson@tees.ac.uk

J. A. Douglas · D. J. Stensel

School of Sport, Exercise and Health Sciences, Loughborough

University, Loughborough, UK 